RYAN L. BOYD AND PAUL KAPOOR

\section{PSYCHOLOGICAL PROFILING AND EVENT FORECASTING USING COMPUTATIONAL LANGUAGE ANALYSIS}

Psychologists have long believed that we can discern what makes a person tick by analysing their language. The modern study of language has become a highly sophisticated area of research that leverages computational modelling, objective measures of language, and extensive empirical rigor. The links between a person's mental processes and the words that they say or write have been extensively studied, validated, and applied to fields as diverse as computer science, medicine, sociology, and anthropology, to name just a few. The ability to 'get inside a person's head' by analysing their language patterns from a distance has tremendous appeal and several practical applications, ranging from the patently obvious to the surprisingly nuanced.

\section{SUBSTANCE VERSUS STYLE}

In research on the psychology of language, most scientists have words that have an explicit meaning (e.g., house, friend, bon etc.). Unsurprisingly, there are several direct links between what a person talks about and what they are thinking. Extroverts tend to use more words related to social processes and use more positive

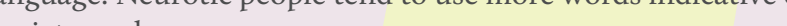

These (perhaps obvious) patterns are grounded in psychological heory and can therefore be extrapolated to a broader

understanding of the individual. The content of a person's

language is reliably diagnostic of their intelligence, political

orientation, personality characteristics, and even how long they ive. The things that occupy a person's mind are not merely

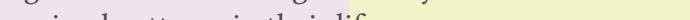

Perhaps more interesting, however, is the style of a person's anguage. An abundance of research in recent years has found that the small, throw-away words in language like articles, pronouns, conjunctions, and so on, are deeply revealing of lowelevel psychological processes. People whose language is highly self-focused (e.g., high rates of words like $\mathrm{Y}$ ', 'me', and 'my') ten (') writing tend to be more analytic in their thoughts, ass') in their whe a somenc's social status and authenticity tend to be reflected in a person's linguistic style more then ts content.

By pairing the analysis of what a person says with how they say ti, we can often paint a remarkably detailed picture of a pers extremely quickly and objectively using computational tools, and

PSYCHOLOGICAL PROFILING

Much of the work in computational psychological profiling is founded on research demonstrating that linguistic patterns are components of language. The quality of language-derived psychological profiles can range from speculative to unbelievably identify an author with nearperfect accuracy using only their language. A language-driven approach to profiling allows us to understand the person behin a given text rather than just the text itself.

Rather than simply taking a threat of violence at face value, we Hlly evaluate the speaker's language for deeper clues. Are they at-risk for a future depressive or schizophrenic episode? Are they obsessive-compulsive, or perhaps prone to conspiratorial thinking? Statistical estimation of these types for psychological vulnerabilities can help to highlight critical

Language-based psychological profiles can also be applied group members think and engage with the world. Recent research found that Islamic State, as a group, shows greater puthoritarianism and religious fervour in their psychological profile (revealed by markers such as low rates of presentfocused and tentative language, plus high rates of religious Whage) relative to al-Qaeda. Moreover, study participants Wested mate in group differences can provide insights into how a group functions, as well what types of people might find these groups appealing.

Psychological profiles can also be built for broader communities and monitore over time. The psychological health of a community can easily be tracked following a tragedy using various data sources, such as newspapers or socia 作 calamitous events ranging from the attacks to mass shootings, finding uniq patterns of coping as they unfold in response to major uphey un.

BEHAVIOURAL

FORECASTING

In a vacuum of information about an

analysis of langurge

can give us important clues about a

person's future behaviours Often, this

approach relies on the relationship

between language and general behavio

patterns. For instance, we find that the

language representative of someone's

values (e.g., family, work ethic, empathy) are strongly related to their regular behaviours, such as attending religious functions, donating time/money to a cause, or even playing games online.

Most of the recent work in languagebased behavioural forecasting based behavioural forecasting focuses on interpersonal behaviours. suicide or spree killings show distinct psycholinguistic fingerprints. When soliciting sex from minos onle insting operations individuals who exhibit high certainty and planning markers in their language are at high risk for repentoffending in the same crime categotes (e. acquisition of child pornography, future attempts to solicit minors).

Similarly, research on group processe finds that linguistic cues related to planning decrease immediately before the betrayal of an ally (along with an increase in positivity and politeness). A failure to linguistically adapt to a changing group menobershp tends to precde members exiting a group, and changes forstic dissolution a relationship.
WHERE DO WE GO FROM HERE?

The inplictions forecasting are farreaching and can represent a double-edged sword. The same language data can be

the psychologically vulnerable can be identified from their language patterns, resulting in a non-negligible risk for targeted exploitation.

Sources who have insight into future plans require particularly high discretion. A person who knows of impending policy changes or upcoming events may show extremely

suble changes in their language pattens. Such changes are often not discennible to an Co approach may not be feasible (or desirable)

in many situations.

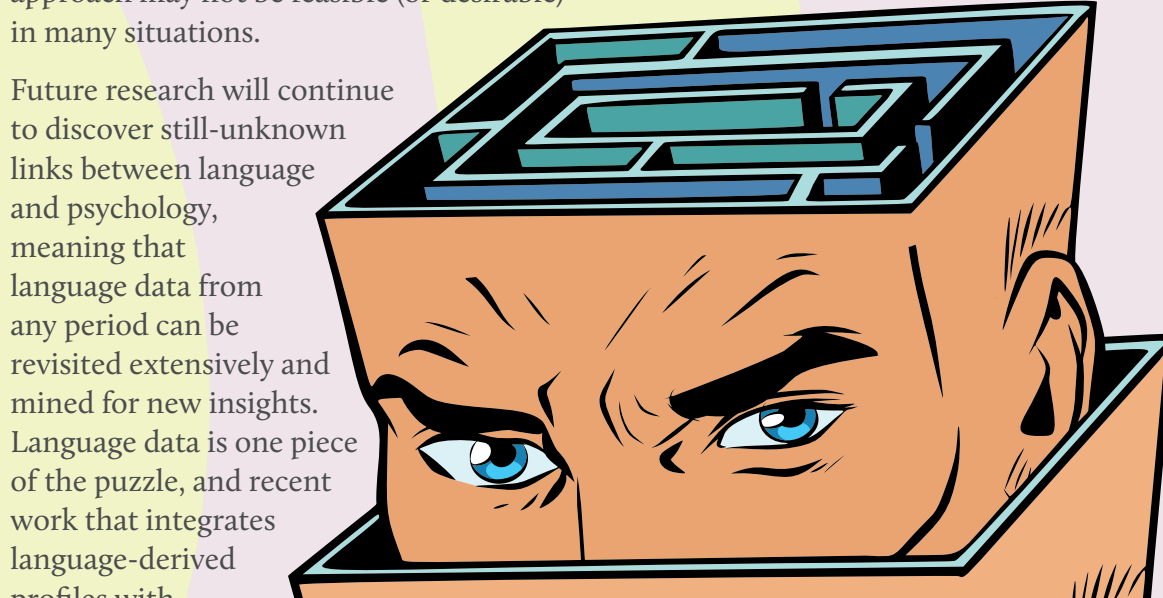

language-derived

profiles with

factors (such as age,

political affiliation,
and images) show

significant promis

for advancing the field

techniques rem

to be developed and will likely be than proactive) as new methods for language a
continue

to emerge.

Dr Ryan L. Boyd is a

computational social scientist and behaviour scientist at the University of Texas at Austin. His research involves the inferen atterns from verbal beha Paul Kapoor is a Senior Princi Gystems Engineer at the North Grumman Corporation and a

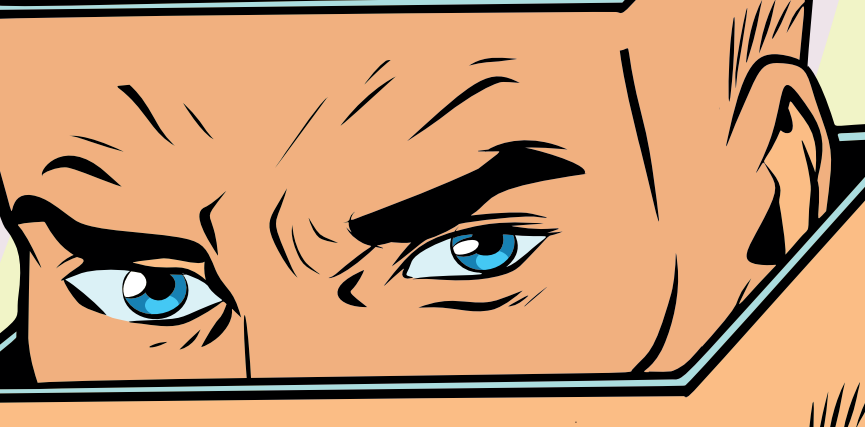

A)

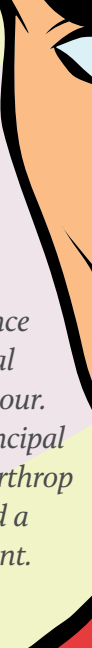

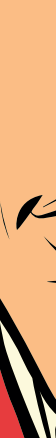

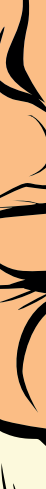

